${ }^{1}$ Dentistry Course, School of Medicine and Public Health of Bahia (BAHIANA), Salvador, BA, Brazil.

${ }^{2}$ Piracicaba Dental School, University of Campinas (UNICAMP) Piracicaba, SP, Brazil.

${ }^{3}$ School of Dentistry, Federal University of Bahia (FOUFBA), Salvador, BA, Brazil.
Corresponding author: Andrea Nóbrega Cavalcanti Dentistry Course, School of Medicine and Public Health of Bahia (BAHIANA) and School of Dentistry, Federal University of Bahia (FOUFBA). Av Silveira Martins, n.3386, Cabula. 41150-100, Salvador, BA, Brazil.

Phone/fax: +55 71 3257-8200

Email: andreancavalcanti@yahoo.com.br

Received: November 10, 2019

Accepted: July 12, 2020

\section{In vitro study of marginal, internal and proximal adaptation of implant-supported single-crown CAD/CAM restorations}

\author{
Kamila Aguiar Figueiredo Alves ${ }^{1}$, Janaina \\ Emanuela Damasceno ${ }^{2}$, Viviane Maia Barreto \\ de Oliveira ${ }^{1,3}$, Luiz Gustavo Cavalcanti Bastos ${ }^{1,3}$, \\ Andrea Nóbrega Cavalcanti ${ }^{1,3, *}$
}

Aim: This study evaluated the precision of a CAD/CAM system by measuring marginal, internal and proximal fits in implantsupported single-crown restorations. Methods: Ten models of the upper arch were made in which implants replaced the upper left premolars. For fabrication of the zirconia infrastructures, titanium bases (TiBase) were coded and scanned using a scan body. A second digital impression was made for the fabrication of prostheses. Silicone impression material was used to determine the internal clearance between the TiBase and infrastructure and between the infrastructure and crown, whose thickness was measured at three points [P1 (cervical), P2 (middle) and P3 (occlusal)] with a stereoscopic microscope at 70x and 100x magnification. One-way ANOVA for repeated measures and the Student t-test were used for the analysis of internal and marginal adaptation. Proximal contacts were analyzed qualitatively. Results: There was no significant difference between the teeth evaluated (Student's t-test; $p>0.05$ ) or between the corresponding points evaluated in either tooth (one-way ANOVA; $p>0.05$ ). Analysis of the internal clearance between the infrastructure and crown demonstrated that all points were significantly different compared to the reference standardized at $100 \mu \mathrm{m}$ (Student's t-test $p<0.0001)$. There was no significant difference between $\mathrm{P} 1$ and $\mathrm{P} 2$, with the thickness at these two points being lower than that obtained at P3 (one-way ANOVA, $p<0.05$ ). The proximal contacts did not coincide with the quality defined by the device. Conclusion: The system tested was unable to produce implantsupported single-crown ceramic restorations with marginal, internal and proximal fits matching the digital workflow, with the inferior fits requiring adjustment prior to cementation.

Keywords: Ceramics. Computer-aided design. Crowns. Data accuracy. 


\section{Introduction}

Restorative dentistry relies on dental impressions for the development of adequate indirect restoration as they provide an extraoral view of the intraoral situation. The marginal adaptation, the interdental or intermaxillary relationship, and the longevity of restorations are directly related to the quality and precision of the impressions ${ }^{1}$.

Conventional intraoral impression using elastomeric material and individual or customized trays is considered the gold standard for fabrication of the working model ${ }^{1}$. However, other techniques have been studied in order to provide more accurate, faster, and more practical results, either for the development of other types of intraoral impressions or for production of the prostheses themselves ${ }^{1-9}$.

The computer-aided design/computer-aided manufacturing (CAD/CAM) technology, a three-dimensional (3D) digital model, is used for the fabrication of restorations ${ }^{1,2,5-9}$. Recent techniques have tried to absorb all the functionality of conventional impression, while aiming to produce an intraoral digital impression that could also result in a virtual 3D model ${ }^{4,10-12}$. In 2012, Sirona launched the Cerec Omnicam oral scanner, which captures 3D intraoral images quickly and accurately without the need for zirconia oxide powder for scanning ${ }^{10,13}$. Advantages of this device include a reduction of the working time and better acceptance by the patient. On the other hand, there are still limitations to be overcome, such as its high cost and problems related to distortion of the digital models and lower precision compared to conventional impression in subgingival areas ${ }^{14}$. However, studies must still prove the effectiveness related to the final quality of the restorations made from images obtained with this equipment.

Some situations make the intraoral scanning process difficult, for example, the presence of subgingival margins ${ }^{15}$. This difficulty is related to both digital impression upon the teeth and upon the implant. However, the advent of digitally coded healing abutments has made it possible to print the implant even at subgingival levels ${ }^{15,16}$.

Another type of encoding was recently developed to prevent the hardness of full-ceramic restorations from damaging the implant platform since the mechanical properties of zirconia differ from those of the metal|13,16,17. A titanium base (TiBase, Sirona, Germany) with a coded scan body (Scan Body, Sirona, Germany) can promote a connection between the implant and zirconia abutment, protecting the integrity of the implant ${ }^{13,16,17}$. TiBase comes in several versions, each of which is compatible with the specific diameter of a particular implant system ${ }^{13}$. Advantages of this system are the perfect adaptation to both the implant and zirconia abutment and the possibility of cementing the TiBase abutment outside the mouth, which would decrease the inflammatory effects caused by residues of the cementing agent ${ }^{13,17}$.

These technologies are quite new and few studies are available to ensure their indication. Furthermore, the adaptation of ceramic restorations is one of the most important criteria used in the clinical evaluation of long-term success ${ }^{18}$. Therefore, the null hypothesis of the present study was that the marginal disadaptation, internal gap and proximal contacts of implant-supported single-crown ceramic prostheses made with 
an intraoral CAD/CAM system (Cerec Omnicam, Sirona, Germany) would not differ from the values established in the digital workflow.

\section{MATERIALS AND METHODS}

In the upper arch of a dental model, the left upper premolars were replaced with implant analogs with an external hexagon connection and regular platform of $4.1 \mathrm{~mm}$. Transfer copings were screwed into the analogs and additional retentions were made with acrylic resin in order to avoid rotation during molding (Figure 1).

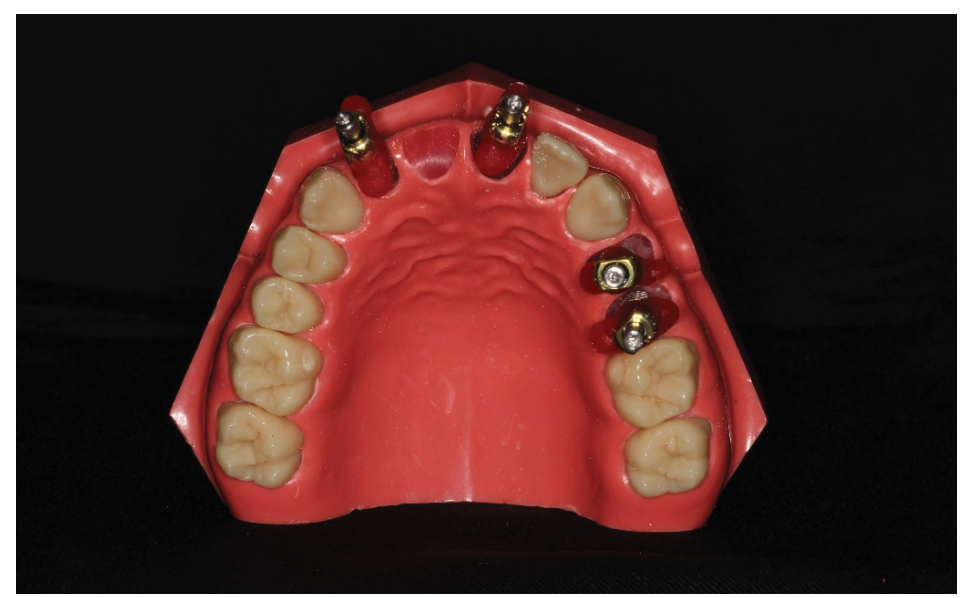

Figure 1. Transfers with additional retention - open-tray technique.

A copy of the upper arch was obtained using polyvinyl siloxane (Elite HD+, Zhermack, Italy) by the impression molding technique for transfer of implants with an open tray. The analogs of the implants were installed in the mold obtained, which was further filled with self-cured acrylic resin, thus obtaining the master model (Figure 2). The analogs were stabilized following the orientation of the alveolus at the gingival level using sticky wax. These procedures were repeated, producing 10 similar replicas of the upper arch.
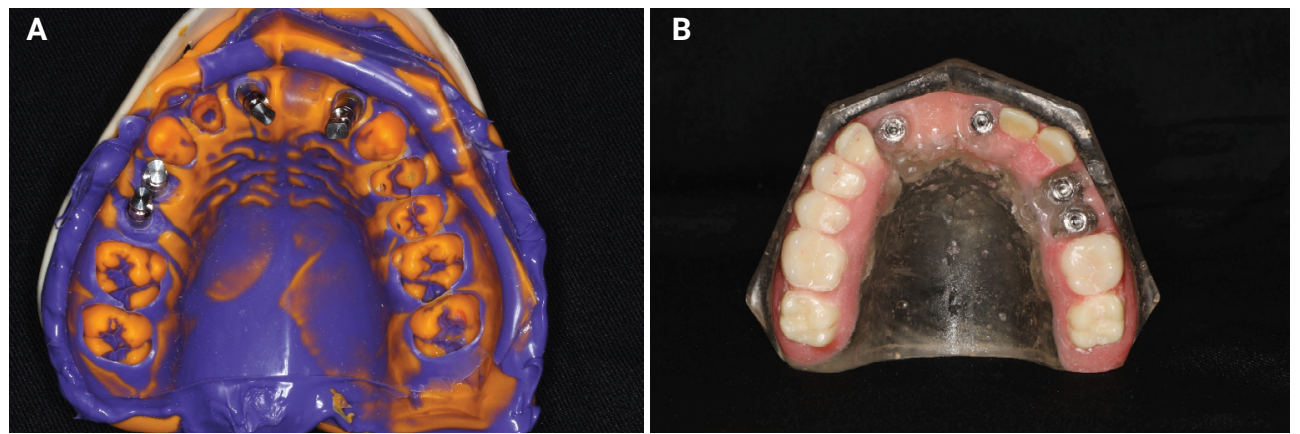

Figure 2. A: Silicone mold with installed analogs. B: Master model. 


\section{Zirconia abutments}

In each replica of the upper arch, a titanium base (TiBase, Sirona, Germany) was screwed on top of the analog. A coding scan body (Scan Body, Sirona, Germany) was then adapted. The 10 replicas were scanned with a Cerec Omnicam oral scanner (Sirona, Germany) (Figure 3).
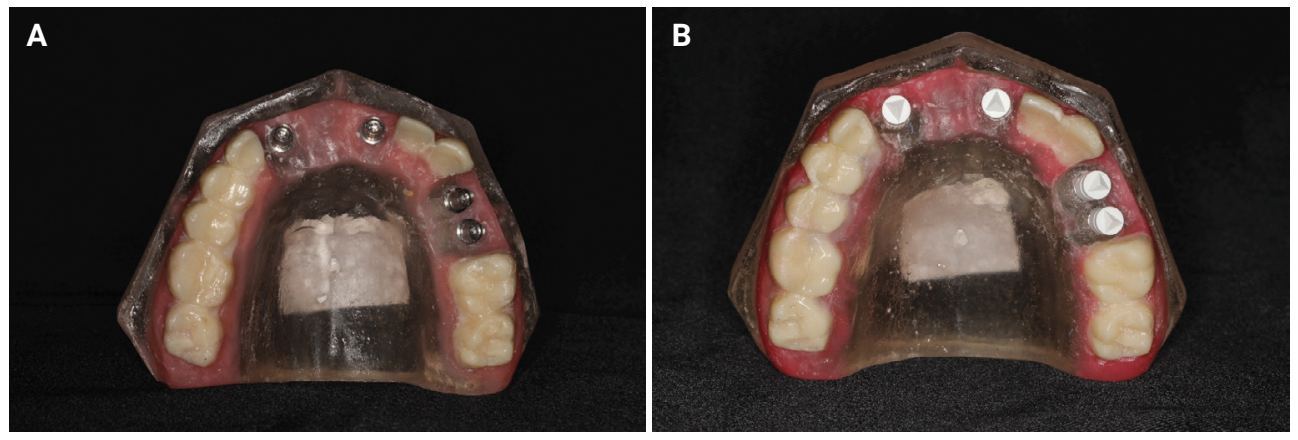

Figure 3. A: Working model with installed TiBase. B: Working model with scan bodies installed in the TiBase.

Abutments were milled (inLab MC XL, Sirona, Germany) from monolithic zirconia blocks (inCoris ZI meso, Sirona, Germany) and sintered (inFire HTC speed, Sirona, Germany) for 135 minutes, resulting in 10 abutments for each left upper premolar.

\section{Ceramic restorations}

The abutments were positioned on the TiBase and a second scan of the 10 replicas was done using the same equipment. The scanned images resulted in 10 feldspathic ceramic crowns (Cerec Blocs, Sirona, Germany) for each tooth evaluated, following the design determined. The marginal adaptation and internal gap were standardized at $100 \mu \mathrm{m}$ based on references cited in the literature that consider this value to be clinically acceptable ${ }^{19-22}$.

\section{Evaluation of proximal contacts}

Carbon strips $(12,21$ and $40 \mu \mathrm{m}$ thick) were used for the evaluation of proximal contacts. For each replica, the evaluation was performed between the canine and first upper left premolar. Considering that digital planning established a programmed distance of the proximal contact of $25 \mu \mathrm{m}$, its quality was considered adequate when the $21-\mu \mathrm{m}$ carbon strip was able to register the contact without crushing or tearing. For this analysis, the carbon strip was placed on the distal proximal surface of the canine and the crown of the premolar was then adapted. The carbon strip was moved horizontally to register the contact pressure. The other thicknesses were used to verify pressures lower or higher than the defined standard.

The proximal contact was classified as weak, close to the standard or strong as follows: weak - without carbon marking; close to the standard - there was marking 
without the carbon strip tearing or crushing, and strong in the case of tearing and/or crushing of the carbon strip. After this analysis, the contact points and interference areas were removed.

\section{Evaluation of marginal disadaptation and internal gap (TiBase $\mathrm{x}$ abutment and abutment $x$ crown)}

For evaluation of marginal adaptation and internal gap between the abutment and TiBase, light-viscosity polyvinyl siloxane was injected into the abutment, which was then positioned on the respective TiBase previously lubricated with water-soluble gel. The abutment, impression material and TiBase assembly was placed in a guide plane and a $5-\mathrm{kg}$ load was applied for 5 minutes over the abutment. After curing, the abutment with the polyvinyl siloxane film was separated from the TiBase (Figure 4).

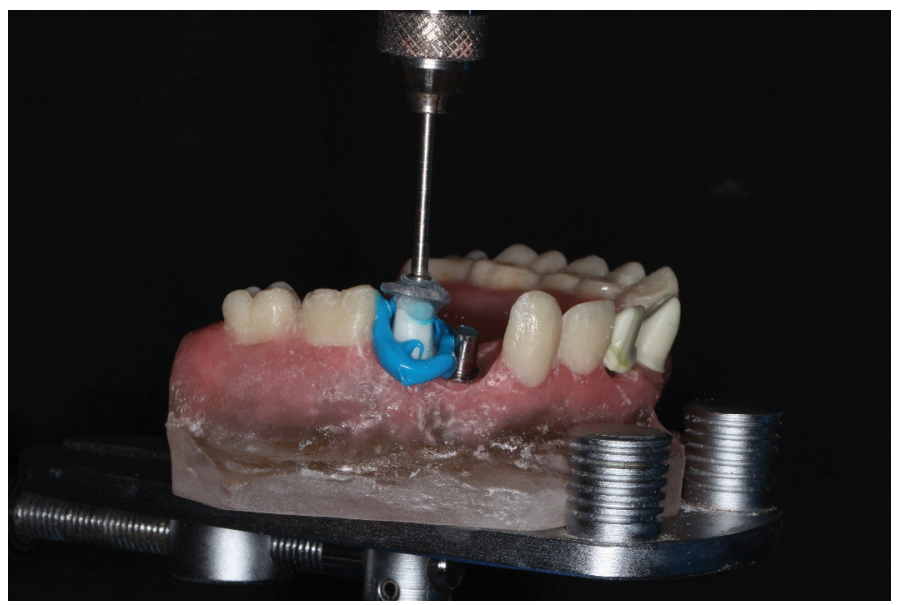

Figure 4. Placement of the abutment-silicone set on the TiBase.

With the polyvinyl siloxane at regular viscosity (Elite HD+, Zhermack, Italy), the inner part of the film-abutment assembly was filled and then positioned in the center of a quadrangular mold, marked with tooth information and surfaces (Figure 5A). The abutment was subsequently separated from the impression material so that the whole piece was filled. Central markings were made on the labial, palatal, mesial and distal surfaces with a permanent pen that served as a cutting guide. Using a microtome blade, the set was divided into 4 parts (Figure 5B). The blade was replaced after cutting each piece.

The films between the abutment and crown were obtained s described above. The images were obtained with a stereoscopic microscope (Opton, Anatomic, China) at 100x magnification for the TiBase and pillar replica and at 70x magnification for the pillar and crown replica. Corel Draw x6 (Corel Corporation, Canada) was used to measure the film thickness corresponding to the marginal misalignment and internal gap of the interfaces. A ruler was used to allow standardization of the measurements. 


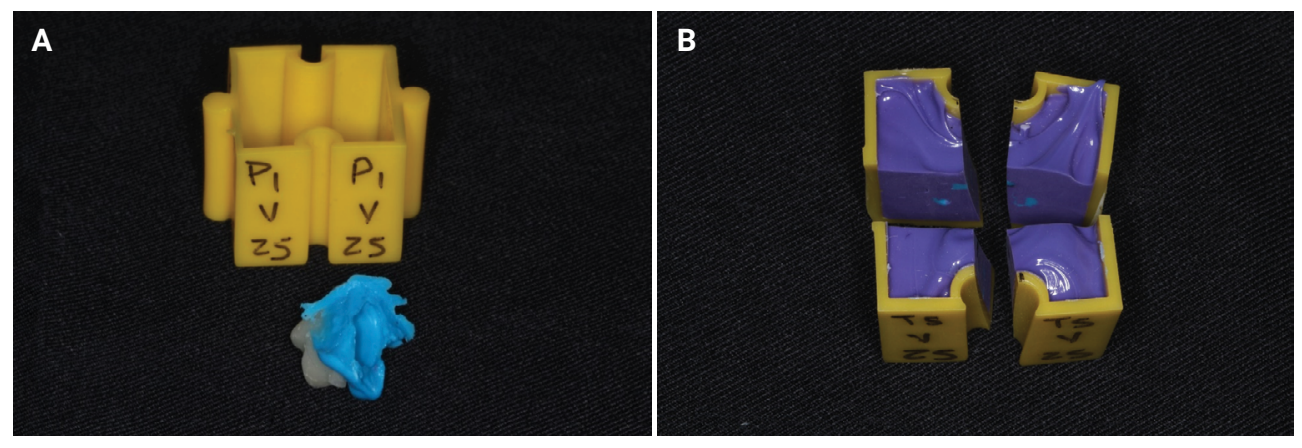

Figure 5. A: Square mold and abutment-film set. B: Quadrangular mold cut into 4 parts.

On each surface (labial, palatal, mesial and distal), 3 measurements were performed at different sites throughout the film (P1: cervical, P2: middle, and P3: occlusal); thus, 12 measurements were taken per film (Figure 6).

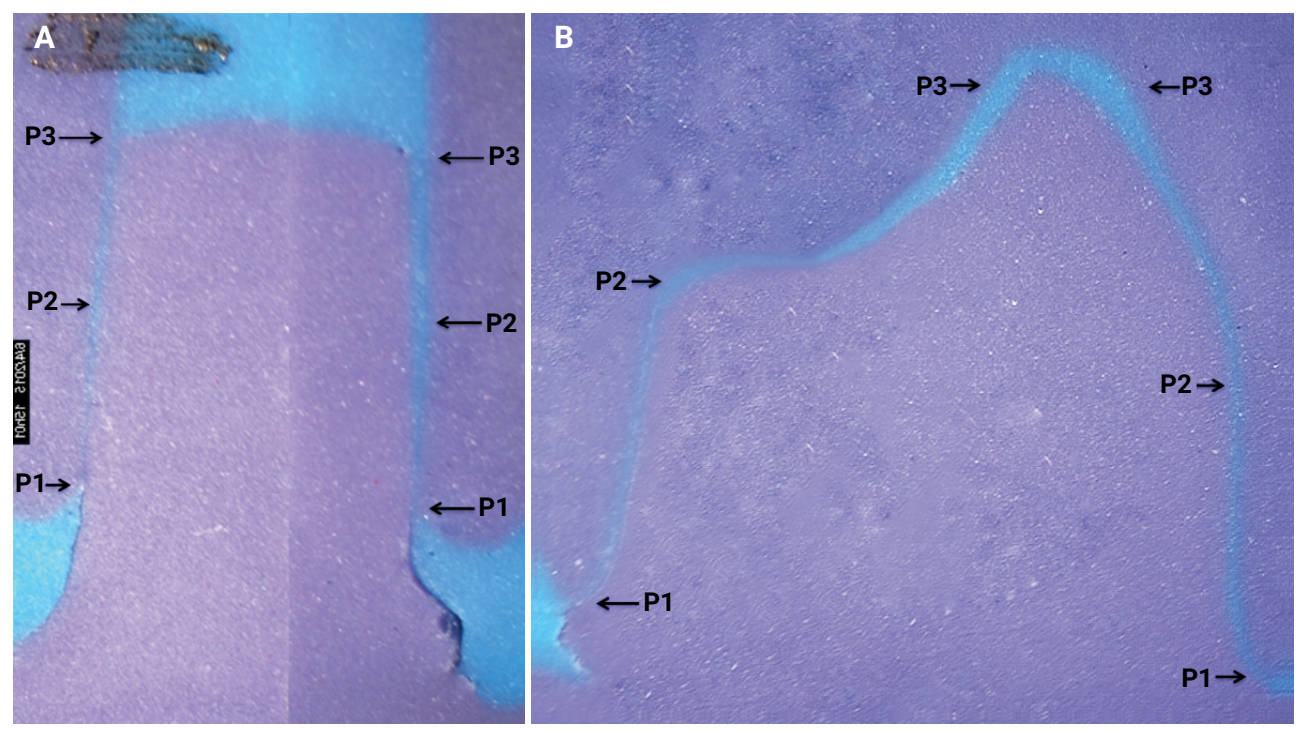

Figure 6. Measurement points (P1, P2 and P3) in TiBase (A) and crown (B).

\section{Statistical analysis}

First, exploratory analysis of the data was performed to verify the homogeneity of variances and to determine if the experimental errors had a normal distribution. Two calibrated researchers performed the analyses. Inferential statistical analysis was done using the SAS 9.1 and Bioestat 5.3 programs, with the level of significance set at $5 \%$. The Student t-test for one sample was used for the comparison of the marginal and internal measurements in relation to the standard provided by the manufacturer. Repeated measures analysis of variance (one-way ANOVA) was applied to compare 
the three points (marginal and internal) evaluated in each tooth. Finally, the Student t-test was used to compare marginal and internal measurements between the two premolars evaluated. Contact points were analyzed only qualitatively.

\section{RESULTS}

\section{Internal and marginal adaptation}

Tables 1 and 2 show the comparison of the mean and standard deviation of the marginal disadaptation and internal gap values between the ceramic infrastructure and TiBase and between the single crown and ceramic infrastructure.

Table 1. Mean and standard deviation of marginal disadaptation and internal gap between the ceramic infrastructures and TiBase.

\begin{tabular}{lccc}
\hline & Tooth 24 & Tooth 25 & Standard \\
\hline P1 & $71.4 \mu \mathrm{m}(18.4) \mathrm{Aa}$ & $76.3 \mu \mathrm{m}(23.6) \mathrm{Aa}$ & \\
\hline P2 & $55 \mu \mathrm{m}(36.8) \mathrm{Aa}$ & $59.3 \mu \mathrm{m}(41.1) \mathrm{Aa}$ & - \\
\hline P3 & $55.6 \mu \mathrm{m}(44.4) \mathrm{Aa}$ & $51.9 \mu \mathrm{m}(84.1) \mathrm{Aa}$ & \\
\hline
\end{tabular}

Means followed by different letters differ significantly $(p<0.05)$. Lower case letters compare teeth at each point. Capital letters compare the points in each tooth.

Table 2. Mean and standard deviation of marginal disadaptation and internal gap between single-unit prosthesis and ceramic infrastructure.

\begin{tabular}{lccc}
\hline & Tooth 24 & Tooth 25 & Standard \\
\hline P1 & $169 \mu \mathrm{m}(48.5) \mathrm{Ba}^{\star}$ & $228 \mu \mathrm{m}(92.1) \mathrm{Ba}^{*}$ & \\
\hline P2 & $274 \mu \mathrm{m}(151.4) \mathrm{Ba}^{*}$ & $219 \mu \mathrm{m}(57.4) \mathrm{Ba}^{*}$ & $100 \mu \mathrm{m}$ \\
\hline P3 & $541.5 \mu \mathrm{m}(180.2) \mathrm{Aa}^{*}$ & $646.75 \mu \mathrm{m}(392.6) \mathrm{Aa}^{*}$ & \\
\hline
\end{tabular}

Means followed by different letters differ significantly $(p<0.05)$. Lower case letters compare teeth at each point. Capital letters compare the points in each tooth. Asterisks indicate a significant difference compared to the standard of the device.

No statistically significant difference was noted in the adaptation of the ceramic infrastructure and TiBase at the points evaluated in either premolar (Student's t-test; P1: $p=0.67, P 2: p=0.76, P 3: p=0.85$ ). In addition, no differences were found between the points evaluated in either premolar (one-way repeated measures ANOVA; first upper left premolar: $p=0.61$, second upper left premolar: $p=0.59)$. The standard was not tested because of the absence of a spacing reference.

Evaluation of the adaptation between the single crown and ceramic infrastructure showed that all marginal and internal points differed significantly from the standard of the instrument (Student's t-test for one sample; $p<0.0001)$. Significant differences between the upper left premolars were not observed at any of the points evaluated (Student's t-test; P1: $p=0.10, P 2: p=0.28, P 3: p=0.48$ ). When the points were compared to each other, the values obtained at P1 and P2 were statistically similar and were lower than those obtained at P3 in both premolars (one-way repeated measures ANOVA; first upper left premolar: $p=0.0006$, second upper left premolar: $p=0.0003$ ). 


\section{Analysis of proximal contact}

The quality of the proximal contacts between the canine and first left upper premolar was established in $25 \mu \mathrm{m}$. The quality of the proximal contacts varied considerably. The contact was classified as weak in three teeth, as weak or close to the standard value in three other, as close to the standard value or strong in two, and as strong in the other two.

\section{DISCUSSION}

The CAD/CAM system is an important advancement in restorative dentistry and a good alternative to conventional methods ${ }^{9,23}$. The fabrication of prostheses with this system tends to eliminate many manual interventions and provides accurate, reproducible and favorable results $\mathrm{s}^{5,6,9,24,25}$.

The clinical success and longevity of indirect restorations are closely related to marginal adaptation and internal gap. For this reason, the definition of clinically acceptable values of minimum and, especially, maximum disadaptation has been of scientific interest. Clinically acceptable values of internal gap vary considerably in the literature. Reported values range from 50 to $100 \mu \mathrm{m}^{18-20}$, and less than $100 \mu \mathrm{m}^{27,28}$ or $120 \mu \mathrm{m}^{22}$, with the last being the most cited in the literature. The authors obtained this value in a 5-year clinical study, in which more than 1,000 indirect restorations were fabricated and evaluated 22 .

In the present study, replicas were used to determine the values of marginal disadaptation and internal gap and the null hypothesis tested was partially accepted. A similar methodology was also employed in previous studies ${ }^{16,23-25,29}$. Rahme et al. ${ }^{30}$ reported that the uniformity of the results found between the internal gap replica and the cement thickness after cementation supports the use of this type of analysis. However, it should be emphasized that disadaptation in indirect restorations usually varies widely between different evaluators or between values found by the same evaluator ${ }^{31,32}$. This fact agrees with the study of Trifkovic et al. ${ }^{33}$ whose results indicate that the choice of technique for measuring the accuracy of ceramic crowns influences the final results of investigation. Therefore, it is fundamental that rigorous evaluation conditions are created, such as a properly calibrated examiner, and that the measurements are carried out by the same researcher.

In the present study, the standardized design was defined as $100 \mu \mathrm{m}$, which is considered clinically acceptable. However, analysis of the adaptation between crown and infrastructure showed mean values higher than the standar and those obtained in the works cited above 19-22,27,28. Some hypotheses to explain this fact are that the disadaptation is related to the process of obtaining images by digital impression, digital planning for marginal adaptation and internal gap, and degradation of the milling cutters used during the machining process.

Regarding digital impression, Ender et al. ${ }^{1}$ aimed to compare the ability of a reference scanner to achieve high precision and accuracy between conventional and digital complete-arch impressions. Digital impressions were significantly less accurate, with a precision of $32.4 \pm 9.6 \mu \mathrm{m}$ and accuracy of $58.6 \pm 15.8 \mu \mathrm{m}(\mathrm{p}<0.001)$. Deviations of 
the digital models were visible throughout the dental arch. The authors concluded that digital impression is less accurate and provides images with a different pattern of deviation compared to conventional impression images.

Additionally, a phenomenon called "cloud points" reported by Ardekani et al. ${ }^{23}$ and Colpani et al. ${ }^{26}$ can occur during the digital impression process, generating areas with internal imperfections and resulting in adaptive interference in marginal and occlusal areas. Small, angled regions can generate "cloud points" since the smaller the scanned area, the greater the chance of errors in fine detail reproduction ${ }^{14,26}$. Another phenomenon reported in the literature related to disadaptation are the so-called overshooters, which simulate virtual peaks near the incisal and occlusal edges ${ }^{34}$. As there is no elevation of geometry in reality, an increase in internal disadaptation may be generated. These phenomena were initially described for Cerec intraoral cameras but apply to all CAD/CAM systems ${ }^{9,34}$. These facts may explain the differences between P1 and P2 compared to P3 in premolars. Differences in disadaptation in the same regions were also found in the in vivo study by Brawek et al. ${ }^{29}$. The authors considered these differences to be of great importance since large variations in the cement line may cause weakening of the restoration. Another reason that may explain this divergence between points in the present study would be the fact that P3 (occlusal region) coincides with the pre-existing orifice in the zirconia block for the through screw.

Regarding digital planning, most studies have used standards below $50 \mu \mathrm{m}^{23-25,29,33}$, different from the present study that standardized the internal gap at $100 \mu \mathrm{m}$. Although all of these studies reported higher disadaptation values than the standard, the values were considered clinically acceptable because disadaptation was less than $120 \mu \mathrm{m}^{23-25,29,33}$. Brawek et al. ${ }^{29}$, who compared the accuracy of crowns made with two CAD/CAM systems (Lava COS and Cerec AC), used a gap between -40 and $30 \mu \mathrm{m}$ for digital planning. The measurement of the points differed significantly from the values of the digital planning and between the two CAD/CAM systems evaluated $(p \leq 0.05)$. However, according to the authors, the relevance of the difference is debatable because both mean values and their corresponding confidence intervals are below the commonly acceptable threshold. In another study, Ardekani et al. ${ }^{23}$ compared zirconia abutments fabricated with a CAD/CAM system (Tizian CAD/CAM system) and by a traditional method, evaluating their marginal and internal adaptation. Digital planning established margins of $0 \mu \mathrm{m}$ and an internal gap of $45 \mu \mathrm{m}$. The maximum and minimum values found with the CAD/CAM system were 118.81 and $44.87 \mu \mathrm{m}$, respectively. Furthermore, the authors suggested a reduction in internal gap to minimize discrepancies and to obtain values reported as clinically acceptable in the literature. The authors concluded that this CAD/CAM system can compete well with conventional systems, and can achieve good marginal adaptation in vitro.

Yucel et al. ${ }^{18}$ also tested the marginal adaptation and internal gap of crowns made by different methods. Crowns made by the CAD/CAM system were planned with $0 \mu \mathrm{m}$ internal gap, that according to this study, would allow a incompatibility between 40 and $50 \mu \mathrm{m}$ in the Cerec 3 system. The maximum and minimum values found by these authors were 40.9 and $24.3 \mu \mathrm{m}$, respectively. In a later study, Nejatidanesh et al. ${ }^{9}$ found a marginal gap of 32.02 to $74.99 \mu \mathrm{m}$. 
D"Arcy et al. ${ }^{24}$ found results similar to those observed in the present study regarding both the different perceived gaps between the points evaluated in the same tooth and the fact that these gaps were larger than those reported in the literature as desirable standard. The mean ( \pm standard deviation) thickness of the internal marginal gap was $149 \pm 26 \mu \mathrm{m}$ in the control group (range 115 to $231 \mu \mathrm{m}$ ). The mean thickness of the occlusal gaps of the crowns was $290 \pm 125 \mu \mathrm{m}$ (range 164 to $624 \mu \mathrm{m}$ ). The authors emphasized that crowns with good adaptation can be produced with the Cerec 3 system when the internal gap is adjusted to $30 \mu \mathrm{m}^{24}$.

The differences between the standardized values and those found in the measurement of internal crown gap agree with the in vitro study of Moldovan et al. ${ }^{35}$, in which the spacer configuration was applied to the internal gap of -100 $\mu \mathrm{m}$ for crowns fabricated with a Cerec system (Inlab software versions 3.x) in order to obtain an internal fit between 60 and $70 \mu \mathrm{m}$.

The wear of the milling instrument can be a source of error during the fabrication of ceramic restorations and changing these instruments at regular intervals is therefore highly recommended ${ }^{5-9,15}$. In the study by Budak et al. ${ }^{33}$, each crown was machined with a set of new milling cutters in order to minimize the influence of tool wear on the accuracy of dental restorations. However, in clinical situations in which the service of a third-party prosthesis laboratory is used, it is difficult for the dental surgeon to control the wear of these cutters. For this reason, despite its possible influence on the adaptation result, this fact was not considered in the present study.

Another finding of this investigation was that the marginal adaptation and internal gap between the ceramic infrastructure and TiBase were within the clinically acceptable range. The TiBase abutments are made from monolithic zirconia blocks that already come with the prefabricated dowel hole. The zirconia blocks are milled to a large size to compensate for the sintering shrinkage estimated at $25 \%$. The success of this compensation depends on the homogeneity of the pre-sintered zirconia and the software's ability to calculate the shrinkage of the material during the digital design of the prosthesis $5-9,23,26$.

Another important feature of TiBase is the possibility of extraoral cementation with a resin cement. Although there is no specification to standardize the maximum film thickness for resin cements, ISO 9917 recommends $25 \mu \mathrm{m}$ as the maximum value to obtain an adequate adaptation of indirect restorations. Minimum cementing lines favor the longevity of the procedures, minimizing the polymerization contraction stress of the resinous materials and reducing interference of the wet oral environment with their properties ${ }^{9,36}$. In the present work, the disadaptation obtained would require the use of materials with higher thread thickness.

Regarding the proximal contact between the implant-supported crowns and the tooth, the present study found divergence between the values obtained and the standardized values $(25 \mu \mathrm{m})$. It is believed that correct adjustment of the proximal contact helps to seat the restoration directly and minimizes loosening and/or fracture of the components, besides allowing better access for hygiene control ${ }^{37}$. Restorations with strong interproximal contacts are associated with increased tensile stresses between implants ${ }^{37}$. 
The techniques and methods investigated had some limitations that indirectly influenced the results. These limitation indicate the need for further studies to deepen some aspects, for example, to compare different impression techniques and to associate them with cementation. Considering these limitation, it can be concluded that the CAD/CAM system with intraoral digital impression (Cerec Omnicam; Sirona, Germany) was unable to produce single ceramic implant prostheses with marginal, internal and proximal fits that corresponded to the digital planning. However, further studies should be conducted since the data indicate success of the CAD/CAM system even when minimal adjustments to the prosthetic part are required.

\section{CONFLICTS OF INTEREST STATEMENT}

The authors report no conflicts of interest related to this work.

\section{ACKNOWLEDGEMENTS}

We thank the institutions involved: School of Medicine and Public Health (EBMSP) and Institute of Health Sciences of the Federal University of Bahia (UFBA).

\section{REFERENCES}

1. Ender A, Mehl A. Accuracy of complete-arch dental impressions: A new method of measuring trueness and precision. J Prosthet Dent. 2013 Feb;109(2):121-8. doi: 10.1016/S0022-3913(13)60028-1.

2. Al-Abdullah $\mathrm{K}$, Zandparsa R, Finkelman M, Hirayama $\mathrm{H}$. An in vitro comparison of the accuracy of implant impressions with coded healing abutments and different implant angulations. J Prosthet Dent. 2013 Aug;110(2):90-100. doi: 10.1016/S0022-3913(13)60346-7.

3. Vogtlin C, Schulz G, Deyhle H, Jager K, Liebrich T, Weikert S, et al. Comparison of denture models by means of micro computed tomography. Proc Spie. Developments in X-Ray Tomography VIII, 85061S. 2012 Oct 17. doi: $0.1117 / 12.930068$.

4. Syrek A, Reich G, Ranftl D, Klein C, Cerny B, Brodesser J. Clinical evaluation of all-ceramic crowns fabricated from intraoral digital impressions based on the principle of active wavefront sampling. J Dent. 2010 Jul;38(7):553-9. doi: 10.1016/j.jdent.2010.03.015.

5. Papadiochou S and Pissiotis AL. Marginal adaptation and CAD-CAM technology: A systematic review of restorative material and fabrication techniques. J Prosthet Dent. 018 Apr;119(4):545-51. doi: 10.1016/j.prosdent.2017.07.001.

6. Kale E, Yilmaz B, Seker E and Özcelik TB. Effect of fabrication stages and cementation on the marginal fit of CAD-CAM monolithic zirconia crowns. J Prosthet Dent. 2017 Dec;118(6):736-41 doi: 10.1016/j.prosdent.2017.01.004.

7. Menini M, Setti P, Pera F, Pesce P. Accuracy of multi-unit implant impression: traditional techniques versus a digital procedure. Clin Oral Invest. 2018 Apr;22(3):1253-62. doi: 10.1007/s00784-017-2217-9.

8. Alghazzawi TF. Advancements in CAD/CAM technology: options for practical implementation. J Prosthodont Res. 2016 Apr;60(2):72-84. doi: 10.1016/j.jpor.2016.01.003.

9. Nejatidanesh F, Shakibamehr AH and Savabi O. Comparison of marginal and internal adaptation of CAD/CAM and conventional cement retained implant-supported single crowns. Implant Dent. 2016 Feb;25(1):103-8. doi: 10.1097/ID.0000000000000346. 
10. Fasbinder DJ, Dennison JB, Heys D, Neiva G. A clinical evaluation of chairside lithium disillicate CAD/CAM crows: a two-year report. J Am Dent Assoc. 2010 Jun;141 Suppl 2:10S-4S. doi: 10.14219/jada.archive.2010.0355.

11. Meer WJ, Andriessen FS, Wismeijer D, Ren Y. Application of intra-oral dental scanners in the digital workflow of implantolog. PLoS One. 2012;7(8):e43312. doi: 10.1371/journal.pone.0043312.

12. Cook KT, Fasbinder DJ. Accuracy of CAD/CAM Crown Fit with Infrared and LED Cameras. Int J Comput Dent. 2012;15(4):315-26.

13. Dentsply Sirona. The Dental Company. Digital Dentistry [access 2015 Jun 5]. Available from: www.sirona.com.

14. Alves KAF, Damasceno JE, Oliveira VMB, Bastos LGC, Cavalcanti AN. Technologies for impression and manufacturing prosthesis on implants: literature review. J Clin Dent Res. 2019 Jan-Apr;16(1):84-92. doi: 10.14436/2447-911x.16.1.084-092.oar.

15. Cardelli P, Scotti R, Monaco C. Clinical fitting of CAD/CAM zirconia single crowns generated from digital intraoral impressions based on active wavefront sampling. J Dent. 2011 Oct 17. doi: 10.1016/j.jdent.2011.10.005.

16. Mahl D, Glenz F, Marinello CP. [Digital implant impression taking - an overview]. Swiss Dent J. 2014; 124(2):165-86. German.

17. Rosentritt M, Rembs A, Behr M, Hahnel S, Preis V. In vitro performance of implant-supported monolithic zirconia crowns: Influence of patient- specific tooth-coloured abutments with titanium adhesive bases. J Dent. 2015 Jul;43(7):839-45. doi: 10.1016/j.jdent.2015.04.011.

18. Yucel MT, Aykent F, Avunduk MC. In vitro evaluation of the marginal fit of different all-ceramic crowns. J Dent Sci. 2013;8(3):225-30. doi: 10.1016/j.jds.2012.05.009.

19. Hickel R, Dasch W, Mehl A, Kremers L. CAD/CAM: fillings of the future? Int Dent J. 997 Oct;47(5):247-58. doi: 10.1002/j.1875-595x.1997.tb00785.x.

20. Holmes JR, Sulik WD, Holland GA, Bayne SC. Marginal fit of castable ceramic crowns. J Prosthet Dent. 1992 May;67(5):594-9. doi: 10.1016/0022-3913(92)90153-2.

21. Molin MK, Karlsson SL, Kristiansen MS. Influence of film thickness on joint bend strength of a ceramic/resin composite joint. Dent Mater. 1996 Jul;12(4):245-9. doi: 10.1016/s0109-5641(96)80030-3

22. Mclean JW, Von Fraunhofer JA. The estimation of cement film thickness by an in vivo technique. Br Dent J. 971 Aug;131(3):107-11. doi: 10.1038/sj.bdj.4802708.

23. Ardekani KT, Ahangari AH, Farahi L. Marginal and internal fit of CAD/CAM and slip-cast made zirconia copings. J Dent Res Dent Clin Dent Prospects. 2012 Spring;6(2):42-8. doi: 10.5681/joddd.2012.010.

24. D'Arcy BL, Omer OE, Byrne DA, Quinn F. The reproducibility and accuracy of internal fit of cerec 3d CAD/CAM all ceramic crowns. Eur J Prosthodont Restor Dent. 2009 Jun;17(2):73-7.

25. Aktas G, Ozcan N, Aydin DH, Sahin E, Akça K. Effect of digitizing techniques on the fit of implant-retained crowns with different antirotational abutment features. J Prosthet Dent. 2014 May;111(5):367-72. doi: 10.1016/j.prosdent.2013.11.001.

26. Torii M, Tsuchitani Y. Marginal adaptability and fit of ceramic milled inlays. J Am Dent Assoc. 1995 Oct;126(10):1414-9. doi: 10.14219/jada.archive.1995.0053.

27. Leinfelder KF, Isenberg BP, Essig ME. A new method for generating ceramic restorations: a CAD-CAM system. J Am Dent Assoc. 1989 Jun;118(6):703-7. doi: 10.14219/jada.archive.1989.0156.

28. Brawek PK, Wolfart S, Endres L, Kirsten A, Reich S. The Clinical accuracy of sigle crowns exclusively fabricated by digital workflow-the comparison of two systems. Clin Oral Invest. 2013 Dec;17(9):2119-25. doi: 10.1007/s00784-013-0923-5. 
29. Rahme HY, Tehini GE, Adib SM, Ardo AS, Rifai KT. In vitro evaluation of the "replica technique" in the measurement of the fit of Procera crowns. J Contemp Dent Pract. 2008 Feb;9(2):25-32.

30. Dedmon HW. Disparity in expert opinions on size of acceptable margins openings. Oper Dent. 1982 Summer;7(3):97-101.

31. Sorensen JA. A standardized method for determination of crown margin fidelity. J Prosthet Dent. 1990 Jul;64(1):18-24. doi: 10.1016/0022-3913(90)90147-5.

32. Trifkovic B, Budak L, Todorovic A, Hodolic J, Puskar T, Jevremovic D, et al. Application of replica technique and SEM in accuracy measurement of ceramic crowns. Measur Sci Rev. 2012;12(3):90-7. doi: 10.2478/v10048-012-0016-7.

33. Colpani JT, Borba M, Bona AD. Evaluation of marginal and internal fit of ceramic crown copings. Dent Mater 2013; 29:174-80.

34. Pfeiffer J. Dental CAD/CAM technologies: The optical impression (II). Int J Comput Dent. 1999 Jan;2(1):65-72.

35. Moldovan O, Luthardt RG, Corcodel N, Rudolph $\mathrm{H}$. Three - dimensional fit of CAD/CAM made zirconia copings. Dent Mater. 2011 Dec;27(12):1273-8. doi: 10.1016/j.dental.2011.09.006.

36. Liu B, Lu C, Wu Y, Zhang X, Arola D, Zhang D. The effects of adhesive type and thickness on stress distribution in molars restored with all-ceramic crowns. J Prosthodont. 2011 Jan;20(1):35-44. doi: 10.1111/j.1532-849X.2010.00650.x.

37. Guichet DL, Yoshinobu D, Caputo AA. Effect of splinting and interproximal contact tightness on load transfer by implant restorations. J Prosthet Dent. 2002 May;87(5):528-35. doi: 10.1067/mpr.2002.124589. 